\title{
Hope Building and Surviving Domestic Violence: Childhood Experiences
}

\author{
Antoinette Day, Kalpana Goel* \\ School of Psychology, Social Work and Social Policy, University of South Australia, Australia \\ *Corresponding Author: Kalpana.Goel@unisa.edu.au
}

\begin{abstract}
Research suggests that hope is an important element in the development of resilience. Although adversity and trauma can have a devastating effect on people and their world views by diminishing hope, these are also the situations that give birth to hope. This paper seeks to gain an understanding of the role of eco-systems in building hope in the context of children surviving domestic violence (DV). In order to gain insight into this phenomenon, the personal accounts of coping and resilience of eight adults with childhood exposure to domestic violence were examined. The study used a qualitative/phenomenological approach. In-depth face-to-face interviews were conducted by using a semi-structured question schedule. The contents of the interview transcripts were inspected to identify common themes and specific experiences of each participant, focusing on the systems in the individual's life including other individuals, family members, peers, friends and community groups and the aspirations and events that facilitated change and contributed to the development of hope and resilience. Thus, this study proffers the importance of eco-systems in a person's life in building hope and resilience and reiterates the importance of an eco-systems framework that social workers could use to develop resilience research and practice to help those affected with DV in childhood.
\end{abstract}

Keywords Hope, Resilience, Domestic Violence, Childhood Experience

\section{Introduction}

The research in resilience has increasingly drawn attention to both individual and societal factors that contribute to healthy outcomes for those who suffer adversity. There is extensive literature on risk factors and protective factors as two important components in mitigating adversity and building resilience. The literature on resilience suggests that resilience involves an individual exhibiting competent functioning despite facing great adversity (Humphreys, 2007; Richards, 2011; Suzuki, Geffner, \& Bucky, 2008). Amongst the key attributes in the development of resilience are hope, coping and self-efficacy (Gillespie, Chaboyer, \& Wallis, 2007).

Research has shown that hope is associated with success in the areas of academic achievement, athletic performance, psychological adjustment and physical health in children, youth and adults (Bernardo, 2010; Ciarrochi, Heaven, \& Davies, 2007; Snyder, 2002). During times of adversity and trauma, hope allows people to envisage a better future and provides motivation to take action to achieve their goals (Bernardo, 2010; Gillespie et al., 2007; Walsh, 2010).

Hope has both subjective and universal components. It is universal in the sense that it is a necessity of life for survival, and at the same time idiosyncratic or subjective, because the amount and type of hope a person possesses is subject to change, depending on the goals and the life situation of the individual (Levi, Leichtentritt, \& Savaya, 2012). Snyder (2002) also conceptualises hope as a trait-like characteristic or a positive motivational mindset, involving agency and pathway thinking. Hope is being regarded as something that individuals possess, and thus as a trait that some have or may not have. However, there is consideration that it may change, given the life situations of that person. This indicates the relevance of an individual's environment that includes all aspects of life linked to physical, social, cultural, economic and political factors. It also makes reference to the dynamic nature of hope building, emphasising focus on the developmental aspect. Research in more recent years has begun to examine the role of external agents, such as family, friends and community in planning and achieving goals for people.

Ungar (2011) has argued that a process-oriented ecological understanding of resilience is necessary to identify what builds hope and resilience in individuals faced with adverse circumstances. Ungar (2011) believes that relational processes in a person's environment that are context- and culture-specific lead to pathways to resilience. Panter-Brick and Eggerman, studied Afghans who maintained hope in spite of severe sufferings in their life, postulate that "social hope is the bedrock of resilience" as their research participants carried a sense of hope towards accessing the resources that would create social and economic opportunities for their family (2012, p. 381). This 
suggests that social ecological systems beyond individual systems are a way forward to understanding hope and resilience. In this paper we discuss how eco-systems and the interactional processes between and among various systems help building hope and resilience amongst those who have faced adversity in childhood, such as exposure to and experience of domestic violence in the family.

\section{Literature Review}

\section{Domestic Violence and Consequences of Witnessing Domestic Violence}

Exposure to DV has been shown to affect children from infancy into adulthood (Adams 2006; Bogat, DeJonghe, Levendosky, Davidson, \& Von Eye, 2006; Martinez-Torteya, Bogat, Von Eye, \& Levendoski, 2009; Turner \& Kopiec, 2006). Research shows that children suffer in areas including behavioural issues, emotional and social adjustment, physical and psychological health and impaired cognitive development (Adams, 2006; Herrenkohl, T. L., Sousa, Tajima, Herrenkohl, R. C., \& Moylan, 2008; Howell, 2011).

Bogat et al.'s 2006 study with 48 mother/baby dyads found $44 \%$ of children as young as twelve months old who were exposed to severe DV presented with a minimum of one trauma symptom. Research (O’Brien, Cohen, Pooley, \& Taylor, 2012; Turner \& Kopiec, 2006) suggests that the negative effects associated with childhood witnessing of DV can impact on the child's social and mental well-being into adulthood. Children, adolescents and young adults who are exposed to DV on an ongoing basis have been shown to be more likely to develop a range of conditions, including separation anxiety, depression, and eating disorders (Herrenkohl et al., 2008; Hunter, 2012; O’Brien et al., 2012).

\section{Studies on Coping and Resilience in Children Exposed to Domestic Violence}

Mariscal (2012) explains that although domestic violence [DV] has been shown to have serious adverse effects on the lives of children, negative results are not necessarily inevitable. Research has shown that a large portion of children fare well in life, regardless of their experiences of DV. Martinez-Torteya et al. in a longitudinal study assessed "mother-child dyads" when the children were aged 2, 3, and 4 years old and examined the individual characteristics and the family characteristics that assist in predicting resilience in young children exposed to DV (2009, p. 562). The study found that, although the children exposed to DV were 3.7 times more probable to develop either internalising or externalising problems than children who were not exposed to DV, $54 \%$ of the children who were exposed to DV adapted well and were considered to be resilient (Martinez-Torteya et al., 2009, p. 562). Graham-Burmann, Gruber, Howell and Girz's 2009 study with 219 children aged 6-12 found that $20 \%$ rated as resilient, showing "low adjustment problems and high levels of competence" (p. 648). According to a study by Kassis, Artz, Scambor, and Moldenhauer (2013, p. 181) of 5,149 school children exposed to DV $30 \%$ were classified as resilient.

\section{Coping Strategies Used by Children Exposed to Domestic Violence}

Although coping and resilience are depicted as positive abilities, strengths, and processes; becoming resilient may involve both 'healthy' and 'non-healthy' coping strategies. Aymer's study (2008) examined the coping responses of ten adolescent males to domestic violence. The findings revealed the way an individual adapts is partly dependent on what they witness and experience growing up, both within the home and in their wider community. Each of the participants in this study used healthy strategies, such as reading, drawing, sports and counselling, and non-healthy strategies, including violence, substance abuse and dealing drugs. Unhealthy coping strategies are also attributed to the context and culture specific strategies that are relevant to a group of people (Ungar, 2011). Although factors such as family and social supports have been shown as contributors to positive adaptation, the individual's ability or willingness to seek out and obtain support may be a contributing factor to becoming resilient (Shaikh \& Kauppi, 2010). In a study with non-violent men exposed to DV as children, some of the men disclosed that making the decision to end the pattern of family violence contributed to their healing and positive adaptation (Gonzalez, Chronister, Linville, \& Knoble, 2012). Lastly, the literature show self-concept, self-acceptance, high levels of self-esteem, self-efficacy, optimistic thinking and internal locus of control have also been found to have a strong influence in the development of resilience in adolescents (Anderson, Renner, \& Danis, 2012; Alvord \& Grados, 2005; Du \& King, 2013; Zolkoski \& Bullock, 2012).

\section{Theoretical Underpinnings (Hope Theory)}

Often hope is confused with optimism; however, the two concepts are significantly different (Sharabi, Levi, \& Margallit, 2012). Optimism is a persistent belief that positive outcomes are likely to occur rather than negative outcomes (Sharabi et al., 2012). According to Snyder, the concept of hope involves more than wishful thinking, it involves three components: (1) a person's perceived ability to set goals and to achieve those goals, (2) an individual's self-belief that one can devise strategies to reach those goals ("pathways thinking"), and (3) the motivation to follow through and attain those goals ("agency thinking") (Snyder, 2006, pp. 61-62).

Each of the three components of hope must be acknowledged for their individual importance; however, the inter-relationship between these components are what separates hope theory from other constructs, such as self-esteem and self-efficacy (Valle, Huebner, \& Suldo, 2004; Ciarrochi et al., 2007). Therefore, someone who is optimistic will believe that everything will turn out the way they want; however, they may not have the pathways needed 
to pursue and attain those goals (Sharabi et al., 2012, p. 67). Bernardo (2010, p. 945) recommends the addition of "locus of hope" to hope theory, as another dimension of "trait-hope" and suggests that individualism is strongly related to internal locus of hope, while collectivism is strongly connected to external locus of hope (Bernardo, 2010, p. 948).

\section{Eco-Systems and Hope Building}

Research on children exposed to DV has shown the importance of secure attachments with at least one parent in coping and the development of resilience (Gerwirtz \& Edleson, 2007; Howell, 2011; Hunter, 2012; Martinez-Torteya et al., 2009; Suzuki e al., 2008). Conversely, very little, if any, research has investigated the role of external systems in the development of hope and resilience in witnesses of DV.

Yohani (2010) discusses the importance of an ecological approach to building hope in children stating: "children cannot be understood independent of their environment", and "children's development and ultimate growth is based on an interaction between their inherited genetic make-up and environmental factors" (p. 866). Therefore, when working with children it is imperative to consider any systems that affect the child's life including family, school, peers and the wider community. Adams (2006) also discusses the need for counsellors to take a "systemic approach" (p. 338) when working with children who are suffering consequences from living in DV situations.

According to O'Dougherty Wright, Masten, and Narayan (2012), children possess fundamental adaptation systems, such as development of attachments, moral development, systems that assist with modulating emotions, behaviour and information processing. These adaptive systems promote healthy development and assist with recovery from adversity However, these adaptations need a facilitative interaction with the external systems that include family, extended family, friends, religious and educational institutions, community groups and other social systems within society (O'Dougherty Wright et al., 2012; Kirst-Ashman \& Hull, 2009; Yohani 2010). O'Dougherty Wright et al. (2012) state: "If the major threats to children's adaptation are stressors that undermine the development of these protective systems, then it follows that children's ability to recover will be highly dependent on these systems being restored" (p. 22).

To illustrate how various systems impact upon the adaptation and change process, one can turn to Bronfenbrenner's ecological model (1979). The focus of the ecological model is on person-to-environment interaction. This interaction takes place at various levels, defined as microsystem, mesosystem, exosystem and macrosystem. This model approaches individuals' characteristics in interaction with their microsystem that includes family, peer, kinship, extended family and teachers. Interactions between and amongst the microsystems will form the mesosystem of an individual that makes resources available to the individual. The exosystem is the external institutions in which individuals and their associated microsystem interact for services that are made available through policy provision. At a higher level individuals interact with legislation, policy and cultural practices. The individual adaptation and change process is triggered and influenced by these interactions that take place within this environment.

\section{Methodology}

This qualitative study used an interpretive/phenomenological approach for the purpose of gaining rich data and an understanding of the meanings that participants attach to their experiences of DV and becoming resilient (Creswell, 2007; Duffy \& Chenail, 2008; McLeod, 2001; Neuman 2011). An inductive approach was adopted as the intention of the researcher was to formulate theory or to gain conceptual clarity based on the data obtained from the participants (Neuman, 2011; Walter, 2010).

\section{Selection of Research Participants}

Information about the research was disseminated through display of flyers in shopping centers, doctors' surgeries and University information boards. Participants for the study could be either male or female and needed to be aged 18 years or older. The researcher used a purposive/self-selected sample. Respondents had to have been exposed to domestic violence during their childhood and believe that they have adapted well and become resilient adults. Those who believed that discussing their experiences of coping and resilience or their experiences of domestic violence would cause emotional distress were excluded. Participation in the study was voluntary and participants themselves contacted the researcher by telephone to schedule a day, time and place for the interview. Majority of the interviews were held at the University campus. The study was approved by the UniSA Human Research Ethics Committee.

\section{Method of Data Collection}

The data for this study were obtained through a single in-depth interview conducted with each participant. The interviews lasted one to one-and-a-half hours, or until no new themes arose. The researcher used a short list of open-ended questions and prompts to ensure that the interviews covered the main areas of the individual's experiences of coping and resilience during and following exposure to domestic violence and to assist with keeping the conversation on track; additionally, questions were added to the schedule as new themes arose (Walter, 2010, p. 301).

Permission was obtained from all the participants to sound-record the interviews with the intention of transcribing the interview later (Walter, 2010). However, if participants did not wish to be sound-recorded the researcher requested permission to take extensive notes during the interview.

Participants were subsequently offered the opportunity to review the transcription to ensure accuracy of the information. This process ensured that the researcher 
obtained correct information as perceived by the participants themselves. Two of the participants accepted the opportunity to review their transcript. One of these two participants contacted the researcher to offer extra information, as the individual felt that they had not provided a complete picture of their experience.

\section{Data Analysis}

Data were analysed using Moustakas's phenomenological method (Moustakas, 1994, as cited in Creswell, 2007). Once the researcher had gained an overall feeling for the participants' stories, any significant statements, sentences, words and quotes were highlighted, with the aim of understanding the participants' experiences of coping and resilience through the exposure to domestic violence and thereafter throughout the stages of their life.

These specific statements and sentences were grouped into categories, common themes and meanings, which were analysed separately, paying particular attention to the similarities and differences in responses as they emerged. Once categorised into clusters of meanings, the themes were used to develop a textural description of what participants have experienced. The information was then used to build a structural description to establish the "essence" of the experience of coping and becoming resilient (Creswell, 2007, p. 61).

\section{Findings}

The demographics of participants, including, the age, employment status, level of education, perpetrator of the violence and the type of violence witnessed, are provided in Table 1.

Participants spoke openly about their childhood and their experiences of coping and becoming resilient throughout childhood and into adulthood. The findings presented here include categories that establish links in various systems in developing hope and resilience. Findings were grouped into the following categories: (a) meaning of resilience, (b) education, (c) formal support, (d) family support, (e) relationships with parents, (f) having a family, and (g) religious faith. Pseudonyms are used to illustrate participants' account of experiences.

\section{Meaning of Resilience}

Resilience to participants meant a person's ability to be able to "get through" adverse events (in the case of this study, DV) and to "move on", "move forward" and continue on and have a relatively normal life. Jenny stated, "Resilience to me is always getting through because of believing that there is light at the end of the tunnel, so thinking I can get to that light." According to Julie, "Resilience means dealing with situations and finding ways to get through the situations." Ava, when explaining the ability to "get through" or being able to "move past" and "continue on" from an adverse event, provided the following example:

If something was happening in my life today, then being able to sort through that as quickly as I can to continue on so it doesn't halter my everyday life.

These examples clearly indicate hope building through the ability to envision an improvement in functioning and a better situation. Two of the respondents saw resilience as an ability to "bounce back" from a negative experience. May said that resilience was "the ability to bounce back or keep a somewhat normal lifestyle no matter what challenges come your way". Meagan described resilience as "an ability to bounce back from something that has got you down, I guess, and to find strategies to help you do that". This statement suggests goal setting and finding strategies as components of resilience.

Acknowledging and accepting what has happened was believed to be part of being resilient; understanding that although they had been exposed to violence in the home, they had no control over what has happened and they cannot change it. Julie explains:

Table 1. Demographics

\begin{tabular}{cccccc}
\hline Pseudonym & Age & $\begin{array}{c}\text { Employment } \\
\text { status }\end{array}$ & $\begin{array}{c}\text { Education } \\
\text { level }\end{array}$ & $\begin{array}{c}\text { Perpetrator of } \\
\text { abuse }\end{array}$ & Type of abuse experienced \\
\hline Ava & $40 \mathrm{~s}$ & Yes & Tertiary & $\begin{array}{c}\text { Father } \\
\text { Father and } \\
\text { Mother }\end{array}$ & Physical $/$ verbal $/$ mental \\
Joy & $60 \mathrm{~s}$ & Yes & Tertiary & Fhysical $/$ verbal $/ \mathrm{mental}$ \\
May & $70 \mathrm{~s}$ & Yes & Tertiary & Father & Physical $/$ verbal $/ \mathrm{mental}$ \\
Jenny & $50 \mathrm{~s}$ & Pensioner & High school & Father & Physical $/$ verbal $/ \mathrm{mental}$ \\
Julie & $40 \mathrm{~s}$ & Yes & Tertiary & Father and & Pother \\
John & $60 \mathrm{~s}$ & Student & Tertiary & Father & Physical $/$ verbal $/$ mental \\
\hline Meagan & $20 \mathrm{~s}$ & Yes & Tertiary & Father & Physical $/$ verbal $/ \mathrm{mental}$ \\
\hline Lisa & $30 \mathrm{~s}$ & Yes & Tertiary & Father & Physical $/$ verbal $/ \mathrm{mental}$ \\
\hline
\end{tabular}


I guess just your general way you deal with things and cope with things, the outcomes and yeah, from maybe positions that you have been put in, that you don't want to be in, but you have to learn to be there because you can't change it, but you have to learn to find ways to deal with it or cope with it. All of the participants shared the belief that resilience occurred as a result of a developmental process, a journey of growth or something that had developed over time. Lisa explained

Resilience for me, it's a consistent pathway of growth of you know we may get knocked down; it's about getting up again. You know; no matter how hard we get hit, it's about keep moving forward no matter what happens.

Therefore participants believed that being exposed to DV, prolonged periods of aggression and fighting assisted them in finding better ways to cope and become more resilient.

\section{Education}

Seven of the eight respondents had participated in education at a tertiary level. Four of the participants returned to study as mature age students. May returned to do her "matriculation" at high-school at the age of 38, then continued on to obtain a diploma in social work, followed by a degree in theology. Although May felt that women getting married and having children was "all good" in her earlier days, she conveyed the opinion that the "choice should be there".

Joy completed her degree in social work as a mature age student and revealed that she did not feel at the time that obtaining an education for her was important; however, for her children and for young people, especially girls, now having an education is important, saying:

For my children, yes, educating themselves. Not only tertiary education but education of any kind...

Ava felt that "attempting" to educate herself as an adult aged 26 was important to the development of her resilience. She said,

Going back to school was very scary for me and that was just a simple TAFE setting. But it also helped build resilience to realise that I had the capacity to be able to do these things.....

Therefore, although Ava felt apprehensive about returning to study, setting the goal and accomplishing that goal increased her self-efficacy, confidence and hope for a brighter future. John is currently a mature age university student and also studied as an adult to become a police officer. John associated his resilience with being successful saying,

I had good jobs, I'm an ex-copper in Melbourne; I did that job for eighteen years. I had a career with the post office; I had a career with the cops and a career with my own business.
The fact that John believes that having a successful employment history with resilience, may be a reflection of the era that John grew up in and the socialising of men as being the provider for the family.

Julie recalled that education became important to her in high school because it was a way of getting out of the situation she was in, the way to get the job she wanted and to "move out of the house".

Lisa explained that her returning to studies was due to a decision, stating, "I spent time and money on bettering myself." Meagan did not say what she studied, but revealed that she had participated in a TAFE course as well as university studies.

\section{Formal Support}

In regard to formal support, three of the respondents disclosed that they had used counselling services at some stage over the years. One participant divulged that she had used counselling during childhood. Of the remaining people who had received formal support, one in particular sought help on a few different occasions throughout her adult life and believed that each issue was related to her past experience of witnessing DV.

When I had my first child I found myself abusing, physically abusing him when he was about eight months old. That was the first time that I actually realised that I had hit him and I spoke to the mothers and babies nurse about what I had done and she put me in touch with some counselling and it helped me to put behavioural things in place, so I could deal with my anger.

Julie reported, "In recent years I have had some issues and I have had counselling with a psychologist."

\section{Family and Friend}

Grandparents were identified by four of the respondents as a major source of support during childhood. Three of the four participants specifically recollected that it was the maternal grandparents who were supportive. According to Lisa,

My grandma, she was a big support, my mum's mum. She was the one that was always there. I still believe to this day if it wasn't for her I wouldn't be who I am today...

When asked about support during childhood Julie said, "I had my grandparents on my mum's side". Ava also identified the maternal grandparents saying, "Most of my fond memories were of going to the beach as a small child, with mum and spending the day there with her and my grandparents."

Apart from grandparents, three participants revealed that they had received support from close friends and one received support from a neighbour who was seen as a friend. According to Ava, she had two friends at school who were both also experiencing domestic violence at home, one of whom spoke quite openly about her situation and "was quite 
vocal about it"; knowing that she was not alone and that someone else was going through the same thing provided comfort. Ava explained, saying about another friend:

I don't know that um, she understood it, but what she gave me was that ability to say things to her, without her asking a lot of questions and without her intervening too much into it. She would just listen to me

Julie credited her childhood friend and her friend's family for making her the person she had come to be, stating,

I often think I could have been a bit of a wild child because of the situation. I was given so much freedom, but I think her family kept me grounded. I think I would have gone off the rails if it wasn't for them.

\section{Religious Faith}

May explained how Christianity and the church was her main support and contributed greatly towards the development of her resilience. This participant became involved with religion as an adult and saw her spiritual beliefs and God as a source of strength and hope. She attributed this to her acquaintance with a person in her workplace that had influenced her outlook towards life.

I hadn't seen Christianity before like this man had been portraying it and I started to look at Christianity, and for me when I look now back on my [previous] life, that has been the calmer, the one thing that has come in a way [religion] that has helped me to take my time in thinking about things, to reflect on things, to see me as valuable.

\section{Relationship with Parents}

Responses regarding the relationships between the participants and their fathers were quite varied. Three of the participants regarded their relationships with their fathers as close; however, one revealed that contact over the past ten years had been rare. The other two said that they were close to their fathers both during childhood and adulthood and believed that people outside the home thought their fathers were good men. Furthermore they had good childhood memories of their fathers when the violence was not happening and said that their fathers were quite involved with them when they were young. Ava said

I felt we had a good relationship. He was .., he could be quite humorous at times..., he tended too, like to go and do things so, that's something that I remember, that I really enjoyed about him.

Joy also felt that her relationship was "quite close" with her father saying, "I went out with dad and do some gardening and stuff like that." Besides biological fathers, three of the participants considered their mother's current partners more like fathers. Jenny had resentment towards her father, saying, "I don't talk about the biological father much. I'm sorry but I hate him. I don't think of him as my father."
When talking about her children, Jenny said that her stepfather was the main role model for her children, "They're poppy, poppy which is my stepfather, and they know that, that's their pop. Although he was only in my life for seven years, he was more of a father figure to me."

Six participants disclosed that they felt close to their mother. The excerpts from some of the transcripts reveal their attachment to their mothers. Joy said that she felt close to both parents and described them as "both good people". When John was asked about his relationship with his mother, he stated, "God, yeah! She loves me to death and I love her to death. She's always loved me and I've always loved her." Ava largely credited her mother for her resilience. As a child Ava admitted that the effort she put into her schooling was largely because of her: "I think part of that was trying to be the best I can be for her sake, being a good kid for her sake, so that she didn't have more stress." (Ava)

Lisa believed that her relationship with her mother was close; however, she felt that it was not the usual mother/daughter relationship, saying, "We've got more of a friendship rather than a mother/daughter relationship. Like, I love her, and I know she did the best she could with the resources that she had at the time."

\section{Having a family}

Four of the participants believed that having children and wanting to protect them and provide them with a better life was a major influence in becoming resilient. Julie explained,

I think it made me more resilient to the fact that I was never going to be like them. It made me stronger to the fact that I thought, no, my life will never be like that, my children will never see anything like that.

Jenny, after witnessing DV growing up, experienced DV in her own marriage. She said, "I won't let them go through what I've gone through." John also revealed that he had made the decision that violence was not going to be a part of his children's life.

\section{Discussion}

The majority of literature on resilience indicates that resilience is measured by the success or failure of people who experience adversity. This puts the onus on the individual to cope and become resilient. However, the interaction of physical, social, cultural and spiritual systems and its interaction in shaping hope and resulting resilience gets ignored. The focus of this paper is to examine the role of eco-systems and hope-building in the development of resilience in those who have survived childhood exposure to DV.

This study indicated a strong presence of hope as participants shared their goals of having a better life void of violence. The goals included having successful careers, loving and non-violent romantic relationships, having families of their own and providing their children with a safe 
and happy family environment. This can be attributed to "internal locus of hope" as hypothesised and constructed by Du and King (2013). Having goal orientation and taking responsibility oneself helped participants achieve self-satisfaction, self-esteem and self-efficacy, thus having positive outcomes. In addition to having an internal locus of hope, participants in this study also shared experiences of how external environment or eco-systems within their context shaped their aspirations and built hope to live a better life free from violence. This is also conceptualised as "external locus" of hope by Du and King (2013, p. 332). The findings from this study contribute to understanding of interaction with external environment in building hope and resilience include education, formal and informal support from family, peers, family friends, neighbours, and belief in religion.

Educational success has been strongly linked to resilience in previous research (Gonzales et al., 2012; Howell, 2011; O'Brien et al., 2012; Suzuki et al., 2008). O’Brien et al.'s study 2012, with six resilient women who were exposed to DV in childhood also found that four of the six women participated in tertiary education as adults. Suzuki et al. (2008) affirmed the value of education as a way of improving life for nearly half of their research participants. Gonzales et al. (2012) showed that study participants believed that achieving educational goals was an important component in the development of resilience.

The current study supports these findings, with seven of the participants completing education at a tertiary level and considering themselves to be academically successful. The participants appreciated the value of education and believed education as a pathway to reaching their goal of improving their lives.

Support from both internal and external systems has been identified as a major protective factor in the literature (Hunter, 2012; Salami, 2010). In this study three of the participants sought professional help/counselling during their adult life to cope with anger, frustration, depression, anxiety and for marriage and relationship issues. The conscious decisions made to stop the violence and the fact that some of the respondents sought help, suggests a level of "human agency" and motivation as possible indicators of resilience as described by Shaikh and Kauppi (2010, p. 155).

The majority of participants reported major support received from informal support systems, such as a close family member, neighbour, close friend and the Christian church. Maternal grandparents, in particular the maternal grandmother, were reported to be the main source of support throughout childhood. Participants viewed maternal grandmothers as strong, supportive, loving and a positive role model. The other connections identified above provide essential elements for the development of resilience, such as a sense of belonging, positive role models and attachments (Alvord \& Grados, 2005). Additionally, having a connection to community groups including religious groups may for some people come to represent a secondary or in some cases a main attachment figure (Greenfield \& Marks, 2010).
Connection with religion and having faith in Christian values provided a sense of belonging and self-worth for one of the participant. This finding is consistent with those of Panter-Brick and Eggerman's research (2012), where their research participants highly valued religious faith in developing a sense of hope for their future.

Relationships with peers have been shown to be crucial in the well-being of children; rejection by peers is suggested to be a cause of loneliness, feeling isolated, self-blaming, low self-esteem and self-perception (Sharabi et al., 2012, p. 62). This study also suggested that participants saw friends and their families as a major support. One of the participants saw her friend's family as partly responsible for the adult that she had become, believing that they accepted her, kept her grounded and encouraged her.

The majority of the participants in this study reported close relationships with their mothers, describing them as loving and caring. However, only one participant saw her mother as a positive role model, a resilient woman who maintained her composure and provided a stable environment and who was always supportive. The participant who was academically successful perceived her relationships with her family as positive and admitted that she tried to always be the "good kid" to make things easier for her mum. This finding supports the suggestion made by Martinez-Torteya et al. (2009) that positive parenting by mothers who are supportive, non-judgmental and provide warmth assists the positive adaptation of the child in the face of adversity. This does point out that quality of family relationships, especially a proximate relationship, is related to building hope and resilience.

There is little data available on the relationships between the father and children during and after DV. Interestingly the current study found that not all of the participants felt animosity towards their father, even as the perpetrator of violence. This supports the findings of Aymer's qualitative study on "Adolescent males' coping responses to domestic violence" (Aymer, 2008), which reported that all participants had close attachments with their mother; however, some also voiced having positive feelings towards their father. Gonzales et al. also found, in a 2012 study with twelve adult males who were brought up in DV situations, that some of the participants had developed compassion towards their father.

According to $\mathrm{Du}$ and Kings (2013), an external locus-of-hope, specifically "family hope", was positively connected to personal self-esteem and contributed to life satisfaction, while "peer hope" was related to collective esteem (Du \& King 2013, p. 336). Those who had an individualist sense of self were more inclined to put hope in themselves and those who had a collective sense of self also put hope in others (Du \& King 2013, p. 336). The current study also suggests that participants' hopes were attached to significant others as well as themselves. The findings from this study affirm that resilience can be understood as the way individuals navigate within their socio-cultural, economic and physical environment and the opportunities presented to 
them within these environments to negotiate building life in adversity (Pulla, 2013, p. 14; Ungar, 2011).

\section{Conclusions}

This article depicts the use of eco-systems theory in understanding and exploring the different systems that are conducive to building hope and resilience. Systems theory focuses on the connections and the interactions of systems in the environment. Social work practice has long used systems theory as an assessment tool, a foundation for intervention and a focus for change. This study indicates that the ecological systems within the lives of participants provided support and a sense of belonging, contributed to self-esteem, efficacy and encouragement. In some cases external systems such as friends' families and the Christian community facilitated change in behaviour and a change in world view as participants set goals of becoming more like them.

\section{Acknowledgements}

This paper is included here with permission of Dr. Venkat Pulla and Bharat Bhushan Mamidi (Editors) of the book 'Some aspects of community empowerment and resilience', Allied Publishers Pvt ltd, India

\section{REFERENCES}

Adams, C. M. (2006). The consequences of witnessing family violence on children and implications for family counsellors. The Family Journal, 14(4), 334-341.

Alvord, M. K., \& Grados, J. J. (2005). Enhancing resilience in children: A proactive approach. Professional Psychology: Research and Practice, 36(3), 238-245.

Anderson, K. M., Renner, L. M., \& Danis, F. S. (2012). Recovery: Resilience and growth in the aftermath of domestic violence. Violence against Women, 18(11), 1279-1299.

Aymer, S. R. (2008). Adolescent males' coping responses to domestic violence: A qualitative study. Children and Youth Services Review, 30(6), 654-664.

Bernardo, A. B. I. (2010). Extending hope theory: Internal locus of trait hope. Personality and Individual Differences, 49(8), 944-949.

Bogat, G. A., DeJonghe, E., Levendosky. A. A., Davidson, W. S., \& Von Eye, A. (2006). Trauma symptoms among infants exposed to intimate partner violence. Child Abuse and Neglect, 30(2), 109-125.

Bronfenbrenner, U. (1979). The ecology of human development: Experiments by nature and design. Cambridge: Harvard University Press.

Ciarrochi, J., Heaven, P. C. L., \& Davies, F. (2007). The impact of hope/ self-esteem, and attributional style on adolescent's school grades and emotional well-being: A longitudinal study. Journal of Research in Personality, 41(6)1161-1178.

Creswell, J. (2007). Qualitative inquiry and research design: Choosing among five approaches ( $2^{\text {nd }}$ ed.). California: USA Sage Publications.

Du, F., \& King, R., B. (2013). Placing hope in self and others: Exploring the relationships among self-construals, locus of hope, and adjustment. Personality and Individual Differences, 18(1), $332-337$.

Duffy, M., \& Chenail, R., J. (2008). Values in qualitative and quantitative research. Counselling and Values, 53(1), 22-38.

Gerwirtz, A. H., \& Edleson, J. L. (2007). Young children's exposure to intimate partner violence: Towards a developmental risk and resilience framework for research and intervention. Journal of Family Violence, 3(22), 151-163.

Gillespie, B. M., Chaboyer, W., \& Wallis, M. (2007). Development of a theoretically derived model of resilience through concept analysis. Contemporary Nurse: A Journal for the Australian Nursing Profession, 25(12), 124-135.

Gonzalez, G., Chronister, K. M., Linville, D., \& Knoble, N. B. (2012). Experiencing parental violence: A qualitative examination of adult men's resilience. Psychology of Violence, 2(1), 90-103.

Graham-Bermann, S. A., Gruber, G., Howell, K. H., \& Girz, L. (2009). Factors discriminating among profiles of resilience and psychopathology in children exposed to intimate partner violence (IPV). Child Abuse and Neglect, 33(9), 648-660.

Greenfield, E. A., \& Marks, N.F. (2010). Sense of community as a protective factor against long-term psychological effects of childhood violence. Social Service Review. 84(1), 129-147. America. Chicago University Press.

Herrenkohl, T. I., Sousa, C., Tajima, E. A., Herrenkohl, R. C., \& Moylan, C. A. (2008). Intersection of child abuse and children's exposure to domestic violence. Trauma, Violence and Abuse, 9(2), 84-99.

Howell, K. H. (2011). Resilience and psychopathology in children exposed to family violence. Aggression and Violent Behaviour, 16(6)562-569.

Humphreys, C. (2007). Domestic violence and child protection: Challenging directions for practice. Australian Domestic \& Family Violence Clearinghouse, issues paper 13. Retrieved from http://www.austdvclearinghouse.unsw.edu.au/pdf\%20files/issuesp aper_13.pdf

Hunter, C. (2012). Is resilience still a useful concept when working with children and young people? Child, Family, Community Australia, Retrieved from

http://www.aifs.gov.au/cfca/pubs/papers/a141718/cfca02.pdf

Kirst-Ashman, K. K., \& Hull, Jr. G. H. (2009). Understanding generalist practice $\left(5^{\text {th }}\right.$ ed). Belmont, CA, USA, Brooks/Cole Cengage Learning.

Kassis, W., Artz, S., Scambor, C., \& Moldenhauer, S. (2013). Finding the way out: A non-dichotomous understanding of violence and depression resilience of adolescents who are exposed to family violence. Child Abuse and Neglect, 37(2-3), 181-199.

Levi, O., Liechtentritt, R., \& Savaya, R. (2012). Posttraumatic stress disorder patients' experiences of hope, Qualitative Health Research, 22(12), 1672-1684. 
Mariscal, S. (2012). Resilience and strengths among children exposed to intimate partner violence. In V. Pulla., L. Chenoweth., A. Francis., \& S. Bakaj (Eds.), Papers in strengths based practice (pp.191-201). New Delhi, India: Allied Publishers Pvt Ltd.

Martinez-Torteya, G., Bogat, A., Von Eye, A., \& Levendoski, A. (2009). Resilience among children exposed to domestic violence: The role of risk and protective factors. Child Development, 80(2), 562-577.

McLeod, J. (2001). Qualitative research in counselling and psychotherapy. London. UK: Sage Publications.

Neuman, L. W. (2011). Social research methods: Qualitative and quantitative approaches $\left(7^{\text {th }}\right.$ ed). Boston. USA: Pearson Education Inc.

O’Brien, K. L., Cohen, L., Pooley, J. A., \& Taylor, M. F. (2012). Lifting the domestic violence cloak of silence: Resilient Australian women's reflected memories of their experiences of witnessing domestic violence. Journal of family violence, 28(1), 95-108.

O’Dougherty Wright, M., Masten, A. S., \& Narayan, A. J. (2012). Resilience processes in development: Four waves of research on positive adaptation in the context of adversity. In S. Goldstein, \& R. B. Brooks (Eds.). Handbook of resilience in children ( $2^{\text {nd }}$. ed.) (pp. 15-38). New York: Springer. Retrieved from books.google.com.au/books?isbn=1461436613

Panter-Brick, C., \& Eggerman, M. (2012). Understanding culture, resilience, and mental health: The production of hope. In M. Ungar (Ed.), The social ecology of resilience: $A$ handbook of theory and practice (pp. 369-386). New York: Springer.

Pulla, V. (2013). Contours of coping and resilience: The front story. In V. Pulla, A. Shatte., \& S. Warren (Eds.), Perspectives on coping and resilience (pp. 1-24). Delhi, India: AuthorsPress.

Richards, K. (2011). Children's exposure to domestic violence in Australia. Trends \& Issues in Crime and Criminal Justice, no. 419, Australian Institute of Criminology. Retrieved from, http://www.aic.gov.au/publications/current\%20series/tandi/401-42 $0 /$ tandi419.html

Salami, S. O. (2010). Moderating effects of resilience, self-esteem and social support on adolescents' reactions to violence. Asian Social Science, 6(12), 101-110.

Shaikh, A., \& Kauppi, C. (2010). Deconstructing resilience: Myriad conceptualizations and interpretations. International Journal of Arts and Sciences, 3(15), 155-176.

Sharabi, A., Levi, U., \& Margallit, M. (2012). Children's loneliness, sense of coherence, family climate, and hope: Development risk and protective factors. The Journal of Psychology, 146(1-2), 61-83.

Snyder, C. R. (2002). Hope theory: Rainbows in the mind. Psychological Inquiry, 13(4), 249-275.

Suzuki, S. L., Geffner, R., \& Bucky, S. (2008). The experiences of adults exposed to intimate partner violence as children: An exploratory qualitative study of resilience and protective factors. Journal of Emotional Abuse, 8(1-2), 103-121.

Turner, H. A., \& Kopiec, K. (2006). Exposure to inter-parental conflict and psychological disorder among young adults. Journal of Family Issues, 27(2), 131-158.

Ungar, M. (2011). The social ecology of resilience: Addressing contextual and cultural ambiguity of a nascent construct. American Orthopsychiatric Association, 81(1), 1-17.

Valle, M. F., Huebner, S, E., \& Suldo, S. M. (2004). Further evaluation of the children's hope scale. Journal of Psychoeducational Assessment, 22(4), 320-337.

Walsh, J. (2010). Theories for direct social work practice (2 ${ }^{\text {nd }}$ ed.). Belmont, CA, USA: Wadsworth Cengage Learning.

Walter, M. (2010). Social research methods. (2 ${ }^{\text {nd }}$ ed). VIC, Australia: Oxford University Press.

Yohani, S. (2010). Nurturing hope in refugee children during early years of post-war adjustment. Child and Youth Services Review, $32(6), 865-873$

Zolkoski, S. M., \& Bullock, L. M. (2012). Resilience in children and youth: A review. Children and Youth Services Review, 34 (12), 2295-2303. 